\title{
Research on the Viscosity-Temperature Properties and Thermal Stability of Stabilized Rubber Powder Modified Asphalt
}

\author{
Qingwei Ma ${ }^{1,2}$, Zhongyin Guo ${ }^{1}$, Ping Guo ${ }^{2}$, Fayong Yang ${ }^{3}$ and Haibin Li ${ }^{3, *}$ \\ 1 The Key Laboratory of Road and Traffic Engineering, Ministry of Education, Tongji University, \\ Shanghai 201804, China; yycc127@126.com (Q.M.); zz8521g@126.com (Z.G.) \\ 2 Xi'an Highway Research Institute Co., Ltd., Xi'an 710065, China; guoping800808@163.com \\ 3 Institute of Road Engineering, School of Architecture and Civil Engineering, Xi'an University of Science and \\ Technology, Xi'an 710064, China; 19204053024@stu.xust.edu.cn \\ * Correspondence: lihaibin1212@126.com
}

\section{check for} updates

Citation: Ma, Q.; Guo, Z.; Guo, P.; Yang, F.; Li, H. Research on the Viscosity-Temperature Properties and Thermal Stability of Stabilized Rubber Powder Modified Asphalt. Sustainability 2021, 13, 13536. https:/ / doi.org/10.3390/su132413536

Academic Editors: Michael Wistuba, Di Wang, Chiara Riccardi, Libo Yan, Zhanping You, Lily Poulikakos and Ana Jiménez del Barco Carrión

Received: 13 October 2021

Accepted: 4 December 2021

Published: 7 December 2021

Publisher's Note: MDPI stays neutral with regard to jurisdictional claims in published maps and institutional affiliations.

Copyright: (c) 2021 by the authors. Licensee MDPI, Basel, Switzerland. This article is an open access article distributed under the terms and conditions of the Creative Commons Attribution (CC BY) license (https:/ / creativecommons.org/licenses/by/ $4.0 /)$.

\begin{abstract}
A stabilized rubber powder-modified asphalt was provided for the field of rubber asphalt, and the optimal blending amount of stable rubber powder was determined from indicators, such as penetration, penetration index, ductility, softening point, and viscosity at $135^{\circ} \mathrm{C}$. The viscoelastic curve was measured, and the thermal storage stability test showed that the stabilized rubber powdermodified asphalt has significant thermal storage stability. The specific surface area, scanning electron microscope, and differential scanning calorimeters were used to analyze the dispersion state and aggregation state of the rubber powder particles in the stabilized rubber powder-modified asphalt, etc. The swelling state and reaction mechanism of the rubber powder in the stabilized rubber powdermodified asphalt have been characterized. The results show that the temperature sensitivity of the asphalt was improved after the stabilized rubber powder was added. The content of the stabilized rubber powder was determined to be $30 \%$, which effectively reduces the viscosity at $135{ }^{\circ} \mathrm{C}$, and the workability is improved; the impact of rubber powder-modified asphalt was less than that of ordinary rubber asphalt, but the temperature should be strictly controlled to ensure the viscosity of stable rubber powder-modified asphalt; the specific surface area comparison test shows that the stable rubber powder has better performance than ordinary rubber powder and asphalt matrix. The advantage of having a larger contact area enhances the compatibility of stabilized rubber powder with asphalt; scanning electron microscopy and differential scanning calorimeters test results show that the stable rubber powder-modified asphalt is mainly based on the compatibility mechanism, and a series of processes, such as oil absorption swelling-high temperature shear-compatible dispersion, occur.
\end{abstract}

Keywords: road engineering; stabilized rubber powder-modified asphalt; viscosity-temperature curve; microscopic morphology; thermal stability

\section{Introduction}

The excellent performance of ordinary rubber asphalt has been proven in a large number of engineering practices. However, in accordance with the government's environmental protection, energy conservation and emission reduction policies have been introduced. The traditional production methods and use effects of rubber asphalt have been exposed to obvious drawbacks and shortcomings. It has gradually been unable to meet the needs of highway asphalt pavement construction under the current environmental protection situation, and its further development has been severely restricted. The main problems are the limited sources of rubber powder in traditional rubber asphalt, poor high-temperature storage stability, high processing temperature, high energy consumption, and serious flue gas pollution [1-3]. The main reason is due to the obvious differences in physical and chemical properties between asphalt and rubber powder, which makes the compatibility of rubber powder and base asphalt poor, resulting in high viscosity, poor fluidity, poor dispersion, and difficulty in ordinary rubber asphalt. The shortcomings include the mixing 
of the mixture and the difficulty of compacting the road surface. It is easy to produce stratification and segregation between the rubber powder particles and the asphalt, and the disadvantage of poor high-temperature storage stability is caused. It also makes it necessary to process and mix the ordinary rubber asphalt on site, which cannot be transported as a finished product for long distances. The industrialization process and application scope of rubber asphalt are severely limited by the above-mentioned shortcomings $[4,5]$.

At present, the research of Ghazi G. Al-Khateeb [6] shows that the complex shear modulus, rutting factor, and fatigue parameters of asphalt are improved by adding rubber powder, and the rutting resistance and fatigue resistance of the asphalt binder are improved. Zhou Tao [7] and others studied the physical and chemical changes of modified asphalt before and after aging and its aging mechanism. Modified asphalt prepared by microwaveactivated rubber powder was found. Microwave activation made the swelling reaction of rubber powder more violent. Kyu-Dong Jeong [8] et al. studied the performance changes of rubber asphalt at different dosages and temperatures and found that the greater the amount of rubber powder, the greater the content of macromolecules in the asphalt, which is mainly due to the swelling of rubber powder due to oil absorption and swelling in the asphalt. The content of light components is reduced. I.M. Ibrahim [9] studied the preparation of rubber asphalt after pretreatment of waste rubber powder by gamma rays and proved that the rubber asphalt prepared by pretreated rubber powder in terms of high- and low-temperature performance and anti-aging performance is significantly improved than ordinary rubber asphalt. Taha Ahmed [10] showed that the performance level of asphalt binder can be significantly improved by adding rubber powder to the base asphalt. However, part of the excessive rubber powder content is free in the asphalt and cannot be completely integrated with the asphalt. Juan Gallego [11] was able to reduce the compaction and storage temperature of asphalt rubber mixture by adding a warm mixing agent to asphalt rubber. Energy consumption and greenhouse gas emissions have been effectively reduced. The research of Shatanawi [12] showed that compared with ordinary rubber asphalt, the thermal storage stability of rubber asphalt prepared by using desulfurized and activated rubber powder was significantly improved. Wang Xiaofeng [13] uses different rubber powder types, SBS, and its content as variables. The three major indexes of modified asphalt, mechanical indexes, storage stability, and other performance characteristics and modification mechanism were analyzed. The results showed that the rubber powder content of vulcanized rubber powder-modified asphalt has strong sensitivity. Zhang Xiaoliang [14] studied the waste tire rubber powder after being treated with Trans-Polyoctenamer Rubber (TOR). It can be effectively improved for hightemperature performance and elastic recovery ability of rubber powder-modified asphalt, and the compatibility and stability of rubber powder and asphalt were also improved. Li Bo [15] found that the viscosity of rubber asphalt is directly affected by the characteristics of waste rubber powder. The performance of rubber asphalt can be improved by rational selection of waste rubber powder from different sources. Dong Bo [16] found that the compatibility of stable rubber powder and asphalt was significantly enhanced, the viscosity was significantly reduced, and it had good aging resistance and thermal storage stability. Zhang Qing [17] introduced in detail the application of micro-characterization techniques, such as thermo gravimetric analysis method and micro-morphology analysis method, in the research of rubber asphalt-modification mechanism. The micro-mechanism of rubber powder-modified asphalt has provided a reasonable reference.

At present, the stable rubber powder-modified asphalt is still an innovative application in the field of rubber asphalt, and the relationship between the reaction mechanism and the microstructure morphology of the stabilized rubber powder-modified asphalt has been seldom studied. Therefore, indicators, such as penetration, penetration index, ductility, softening point, and viscosity at $135^{\circ} \mathrm{C}$, are used in this article to determine the optimal content of desulfurization rubber powder. Specific surface area analysis, scanning electron microscopy, thermal storage stability test, and differential scanning calorimetric are used to determine the dispersion state and aggregation state of rubber powder particles in the 
stabilized rubber powder-modified asphalt and the viscosity temperature of the stabilized rubber powder-modified asphalt. The curve is constructed, and the swelling state and reaction mechanism of the rubber powder in the stabilized rubber powder-modified asphalt are characterized.

\section{Materials and Methods}

\subsection{Experiment Material}

\subsubsection{Base Asphalt}

The performance of different grades of base asphalt and the modified asphalt produced by the same modifier is quite different, so the first task is to select a base asphalt with good compatibility with stable rubber powder [18]. Asphalt often used in the design of high-grade pavements in Northwest China has been taken into consideration. South Korea's SPC-90\# bitumen was selected as the base bitumen in this article. Its basic physical properties are shown in Table 1.

Table 1. Basic indexes of SPC-90\# base asphalt.

\begin{tabular}{ccccc}
\hline Technical Index & $\begin{array}{c}\text { Penetration }\left(\mathbf{2 5}{ }^{\circ} \mathbf{C},\right. \\
\mathbf{1 0 0} \mathbf{g}, \mathbf{0 . 5} \mathbf{~ s}) / \mathbf{0 . 1} \mathbf{~ m m}\end{array}$ & $\begin{array}{c}\text { Softening } \\
\text { Point } /{ }^{\circ} \mathbf{C}\end{array}$ & $\begin{array}{c}\text { Ductility } \\
\mathbf{5} \mathbf{~ c m} / \mathbf{m i n}, \\
\left.\mathbf{1 5}{ }^{\circ} \mathbf{C}\right) / \mathbf{c m}\end{array}$ & $\begin{array}{c}\text { Dynamic } \\
\text { Viscosity at } \\
\mathbf{6 0} \mathbf{C} / \mathbf{P a} \cdot \mathbf{s}\end{array}$ \\
\hline Measured value & 87.9 & 47.6 & $>100$ & 161.6 \\
Requirements [19] & $80-100$ & $>45$ & $>100$ & $>160$ \\
\hline
\end{tabular}

\subsubsection{Stable Rubber Powder}

At present, ordinary rubber powder is a waste tire rubber powder commonly used in rubber asphalt modification technology. It is a vulcanized rubber powder that is crushed and ground at room temperature. This article uses 40 mesh vulcanized rubber powder, as shown in Figure 1. The rubber powder used in this article is a stable rubber powder, as shown in Figure 2, which is produced by the corresponding vulcanized rubber powder through a purely physical thermo mechanical-twin screw extrusion method. All physical and chemical indexes of stable rubber powder should meet the requirements of Tables 2 and 3.

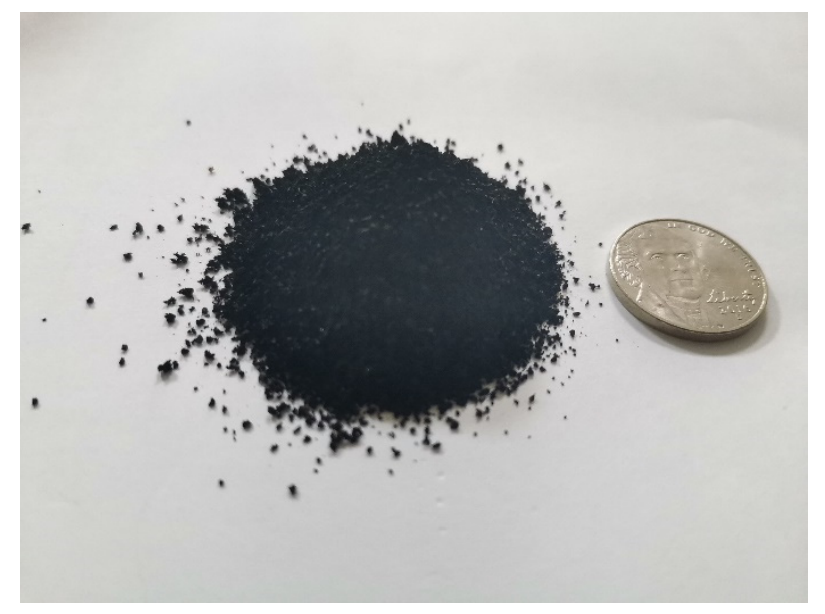

Figure 1. Ordinary rubber powder.

The stable rubber powder is produced by a purely physical thermo mechanical twinscrew extrusion method. After a large shear force in the desulfurization process, various filler systems in the rubber powder are destroyed, and the obvious rubber powder particles appear as spherical. Although there are still a great deal of irregularities on the surface, the burr-like substances on the surface are reduced. The outer diameter of the particles is relatively uniform and fluffy, and the adsorption and infiltration of asphalt and stable 
rubber powder is promoted. In addition, the stable rubber powder is re-extruded and pelletized by waste rubber. It can be seen from Figure 2 that the particle size specifications of the stable rubber powder are not uniform. The largest particle size exceeds $8 \mathrm{~mm}$, and the smallest particle size is less than $3 \mathrm{~mm}$.

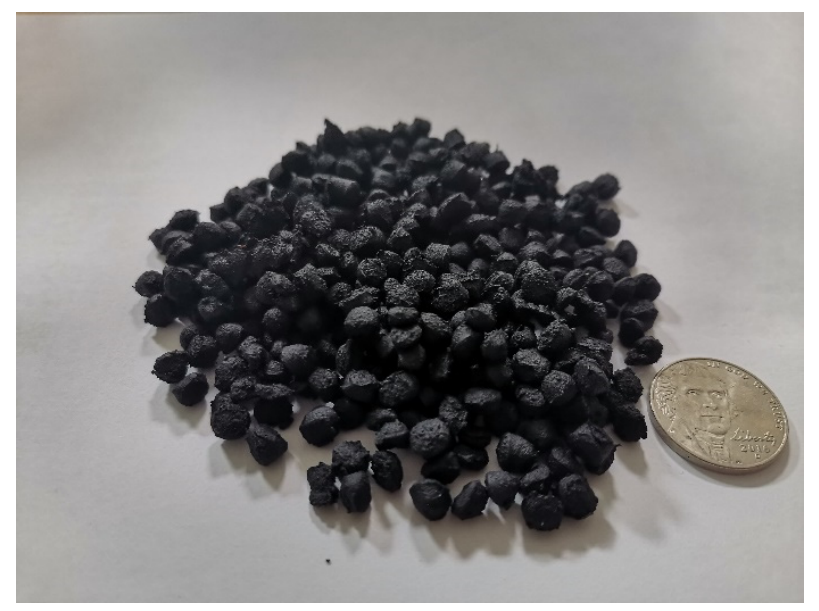

Figure 2. Stable rubber powder.

Table 2. Physical and technical requirements of stable rubber powder [20].

\begin{tabular}{|c|c|c|c|c|}
\hline Pilot Projects & $\begin{array}{l}\text { Relative } \\
\text { Density }\end{array}$ & $\begin{array}{c}\text { Moisture } \\
\text { Content/\% }\end{array}$ & $\begin{array}{c}\text { Metal } \\
\text { Content } / \%\end{array}$ & $\begin{array}{c}\text { Fiber } \\
\text { Content } / \%\end{array}$ \\
\hline Skills requirement & $1.10 \sim 1.30$ & $<1.0$ & $<0.05$ & $<1.0$ \\
\hline Experiment method & JT/T 797 & GB/T 19208 & JT/T 797 & GB/T 19208 \\
\hline
\end{tabular}

Table 3. Chemical technical requirements for stable rubber powder [20].

\begin{tabular}{cccccc}
\hline Pilot Projects & $\begin{array}{c}\text { Natural } \\
\text { Rubber } \\
\text { Content/\% }\end{array}$ & Ash /\% & $\begin{array}{c}\text { Acetone } \\
\text { Extract/\% }\end{array}$ & $\begin{array}{c}\text { Carbon } \\
\text { Black } \\
\text { Content/\% }\end{array}$ & $\begin{array}{c}\text { Rubber } \\
\text { Hydrocarbon } \\
\text { Content/\% }\end{array}$ \\
\hline $\begin{array}{c}\text { Skills requirement } \\
\text { Experiment } \\
\text { method }\end{array}$ & GB $/ \mathrm{T} \mathrm{14837}$ & $\mathrm{GB} / \mathrm{T} 4498$ & $\mathrm{~GB} / \mathrm{T} 3516$ & $\mathrm{~GB} / \mathrm{T} 14837$ & $\mathrm{~GB} / \mathrm{T} \mathrm{14837}$ \\
\hline
\end{tabular}

\subsubsection{Other Materials}

In order to effectively evaluate the basic performance of stabilized rubber powdermodified asphalt and its mixture road performance. In this test, two modified asphalts commonly used in northwestern China were selected as comparative tests. The performance indexes of the two asphalts are shown in Table 4.

Table 4. Basic indexes of ordinary rubber asphalt and SBS-modified asphalt.

\begin{tabular}{|c|c|c|c|c|}
\hline Technical Index & $\begin{array}{l}\text { Penetration } \\
\left(25^{\circ} \mathrm{C}, 100 \mathrm{~g},\right. \\
0.5 \mathrm{~s}) / 0.1 \mathrm{~mm}\end{array}$ & $\begin{array}{l}\text { Softening } \\
\text { Point } /{ }^{\circ} \mathrm{C}\end{array}$ & $\begin{array}{l}\text { Ductility } \\
(5 \mathrm{~cm} / \mathrm{min}, \\
\left.15^{\circ} \mathrm{C}\right) / \mathrm{cm}\end{array}$ & $\begin{array}{c}\text { Dynamic } \\
\text { Viscosity at } \\
180^{\circ} \mathrm{C} / 135^{\circ} \mathrm{C} / \mathrm{Pa} \cdot \mathrm{s}\end{array}$ \\
\hline Ordinary rubber asphalt & 65.1 & 66.5 & 8.5 & 1.194 \\
\hline Requirements & $40-80$ & $\geq 58$ & $\geq 8$ & $1.5 \sim 4.0$ \\
\hline SBS-modified asphalt & 66.0 & 74.4 & 38.2 & 1.550 \\
\hline Requirements & $60 \sim 80$ & $\geq 55$ & $\geq 30$ & $\leq 3.0$ \\
\hline
\end{tabular}




\subsection{Sample Preparation}

At present, the preparation parameters of rubber modified asphalt are: the shear speed is $5000 \sim 6000 \mathrm{r} / \mathrm{min}$, the preparation temperature is controlled at $165 \sim 175{ }^{\circ} \mathrm{C}$, the shear time is about $60 \mathrm{~min}$, and the development is $45 \sim 50 \mathrm{~min}$ in the $175{ }^{\circ} \mathrm{C}$ oven.

\subsection{Characterization Methods}

\subsubsection{Physical Performance Test}

According to the test method stipulated in the Asphalt and Asphalt Mixture Test Regulations, the basic performance tests of the stabilized rubber powder-modified asphalt include penetration, softening point, ductility, and rotational viscosity, etc., according to the "Highway Engineering Asphalt and Asphalt Mixture". T0604, T0606, T0605 and T0628 in the "Material Experiment Regulations" (JTG E20-2019) [19]. In addition, without special explanation, the penetration, ductility, and rotational viscosity mentioned in this article are performed at $25^{\circ} \mathrm{C}, 5^{\circ} \mathrm{C}$, and $135^{\circ} \mathrm{C}$, respectively.

\subsubsection{Determination of Viscoelastic Curve}

The Brookfield rotational viscometer was used to test the viscosity of stabilized rubber powder-modified asphalt at $115^{\circ} \mathrm{C}, 135^{\circ} \mathrm{C}, 155^{\circ} \mathrm{C}$, and $180^{\circ} \mathrm{C}$. The $21 \#$ and $27 \#$ rotors are mainly used in the viscosity test process, and the mass of the sample is $10.0 \mathrm{~g}$ and $11.5 \mathrm{~g}$, respectively. The viscosity of base asphalt (VA), ordinary rubber asphalt (AR), SBS-modified asphalt (SBSMA) and stabilized rubber powder-modified asphalt (DRA) at different test temperatures were measured. The viscosity-temperature curve is established, and the law of viscosity and temperature change is obtained.

\subsubsection{Thermal Storage Stability Test}

The segregation test is used to evaluate the thermal storage stability of the stabilized rubber powder-modified asphalt, and the difference between the upper and lower sections does not exceed $2.5^{\circ} \mathrm{C}$.

\subsubsection{Microscopic Test}

Autosorb-6B specific surface area and pore size analyzer is used to test the specific surface area of the rubber powder after drying the rubber powder in vacuum at $110^{\circ} \mathrm{C}$ for $2 \mathrm{~h}$. Observe the phase structure of the stabilized rubber powder-modified asphalt through JSM-6010 LA scanning electron microscope (SEM) observation technology.

\subsubsection{Thermal Analysis Test}

A comprehensive thermal analyzer produced by NETZSCH in Germany was used to characterize the changes in the internal aggregation state of the stabilized rubber powder, and the micro-mechanism of the stabilized rubber powder-modified asphalt was revealed. The test heating rate is $10^{\circ} \mathrm{C} / \mathrm{min}$, the nitrogen flow rate is $20 \mathrm{~mL} / \mathrm{min}$, and the test temperature range is from room temperature to $800^{\circ} \mathrm{C}$.

\section{Test Results and Analysis}

\subsection{Physical Index of DRA}

SPC90\# base asphalt was used, and stabilized rubber powder-modified asphalt was prepared according to five weight ratios of $21 \%, 24 \%, 27 \%, 30 \%$, and $33 \%$. The content of ordinary rubber powder in rubber asphalt is $20 \%$. The basic physical index results were shown in Table 5.

It can be seen from Table 5 that compared with the VA penetration of the base asphalt, the penetration of the stabilized rubber powder-modified asphalt is reduced by about $21.15 \%$, which is a significant decrease. It shows that with the addition of stabilized rubber powder, the asphalt has a tendency to harden, which reduces the flexibility of the asphalt. The content of stable rubber powder is increased, and the penetration of DRA is first increased and then decreased, which shows that the flexibility of DRA is effectively 
improved within $21 \% \sim 27 \%$ of stable rubber powder. The penetration index reaches the maximum when the rubber powder content is $27 \%$. The main reason is that the solubility of the stable rubber powder in the asphalt has a peak. The stabilized rubber powder absorbs the light components in the asphalt during the initial stage of adding swelling and decomposition, causing the asphaltene content to increase indirectly. When the content of the rubber powder exceeds $27 \%$, the more difficult it becomes to dissolve rubber powder particles that form, which are easy to form. The phenomenon of agglomeration of rubber powder particles is visually manifested as the residual rubber powder particles obstruct the penetration of the needle penetration, resulting in a decrease in the penetration value.

Table 5. Physical indicators of stabilized rubber powder-modified asphalt.

\begin{tabular}{|c|c|c|c|c|c|c|}
\hline $\begin{array}{c}\text { Rubber Powder } \\
\text { Content } / \%\end{array}$ & Penetration $/ 0.1 \mathrm{~mm}$ & $\begin{array}{c}\text { Cone } \\
\text { Penetration } / 0.1 \mathrm{~mm}\end{array}$ & Ductility/cm & $\begin{array}{l}\text { Softening } \\
\text { Point } /{ }^{\circ} \mathrm{C}\end{array}$ & $\begin{array}{l}\text { Viscosity at } \\
135^{\circ} \mathrm{C} / \mathrm{Pa} \cdot \mathrm{s}\end{array}$ & $\begin{array}{l}\text { Viscosity at } \\
180{ }^{\circ} \mathrm{C} / \mathrm{Pa} \cdot \mathrm{s}\end{array}$ \\
\hline 21 & 65.4 & 39.56 & 9.5 & 58.3 & 1.765 & 0.551 \\
\hline 24 & 67.2 & 41.22 & 11.2 & 60.2 & 2.012 & 0.594 \\
\hline 27 & 69.3 & 42.23 & 13.5 & 63.5 & 2.421 & 0.786 \\
\hline 30 & 68.2 & 42.01 & 12.8 & 63.8 & 2.652 & 0.858 \\
\hline 33 & 65.9 & 39.41 & 10.2 & 60.5 & 3.011 & 0.977 \\
\hline $\mathrm{AR}$ & 63.1 & 36.50 & 8.5 & 66.5 & 8.6 & 1.594 \\
\hline VA & 87.9 & - & $>100$ & 47.6 & - & - \\
\hline
\end{tabular}

The change trend of the penetration degree of the stabilized rubber powder-modified asphalt is similar to that of the penetration degree, and both appear to be increased first and then decreased. It shows that the addition of stabilized rubber powder has a more obvious change in the flexibility of asphalt, and the cone penetration index reaches the maximum value when $27 \%$ rubber powder is added. The content of stabilized rubber powder is increased, and the softening point of stabilized rubber powder-modified asphalt first increases and then decreases, and reaches an extreme value of $63.8^{\circ} \mathrm{C}$ at $30 \%$ content, which is about $47.6{ }^{\circ} \mathrm{C}$ higher than the softening point of base asphalt at $47.6^{\circ} \mathrm{C}$. At $34.1 \%$, it can be seen that the increase in the amount of stabilized rubber powder is beneficial to the improvement of the high-temperature performance of the stabilized rubber powdermodified asphalt. The content of stabilized rubber powder increased from $21 \%$ to $27 \%$, and the ductility increased by about $42.1 \%$, which was about $145.5 \%$ higher than that of base asphalt at $5{ }^{\circ} \mathrm{C}$ and $6-\mathrm{cm}$ ductility, and about $58.8 \%$ higher than that of ordinary rubber asphalt. With the increase in the amount of stabilized rubber powder, the Brook-field viscosity of stabilized rubber powder-modified asphalt at $135^{\circ} \mathrm{C}$ and $180{ }^{\circ} \mathrm{C}$ was increased, but the trend is relatively flat. Compared with ordinary rubber asphalt, the viscosity is reduced by about $38.9 \%$ to $65.6 \%$, and the viscosity of the stabilized rubber asphalt is about $38.9 \% \sim 65.6 \%$. The $135{ }^{\circ} \mathrm{C}$ viscosity is not more than $3 \mathrm{~Pa} \cdot \mathrm{s}$, which complies with the US SHRP standard on the viscosity of modified asphalt.

The stabilized rubber powder-modified asphalt prepared with different rubber powder content was compared. In order to make it have good performance, it was recommended that the optimal content range of stable rubber powder was $27 \sim 30 \%$. The subsequent tests in this paper adopt $30 \%$ content preparation test sample.

\subsection{Viscosity-Temperature Characteristic Analysis}

The viscosity of VA, AR, SBSMA, and DRA at different test temperatures are measured, the viscosity-temperature curve is established, and the law of viscosity and temperature changes are obtained. The test results are shown in Figures 3 and 4. 

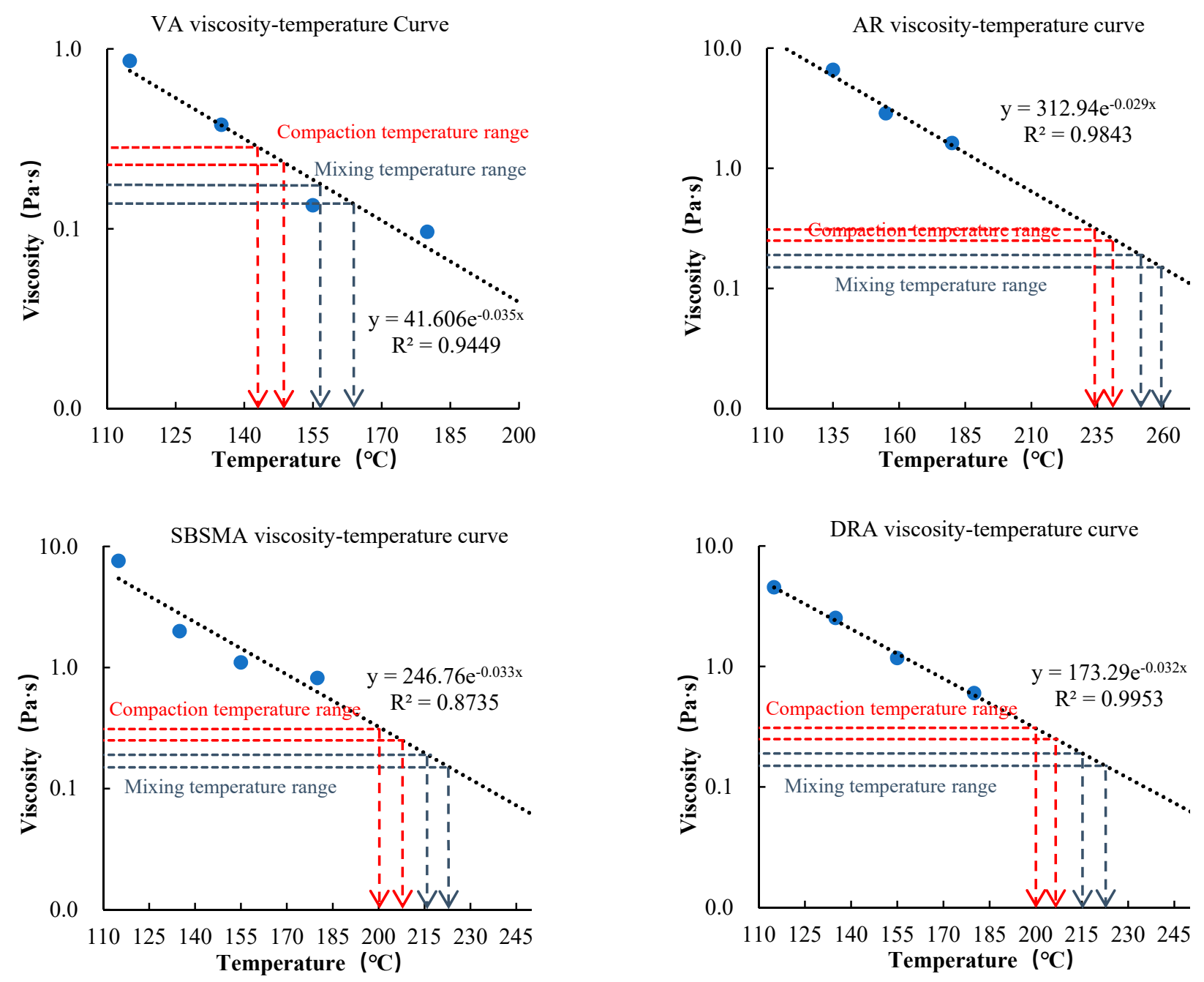

Figure 3. Viscosity of different types of asphalt changes with temperature.

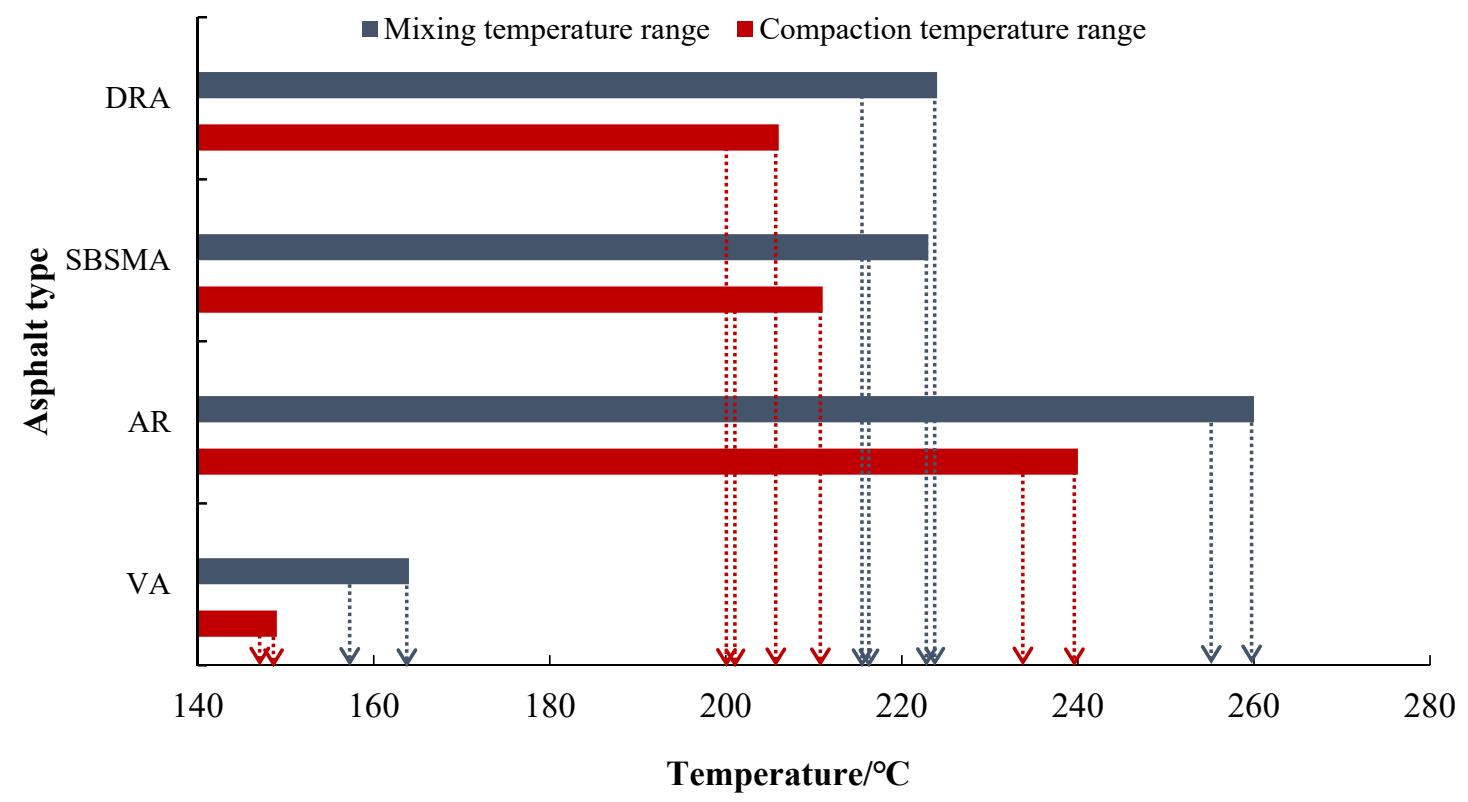

Figure 4. Comparison of different asphalt mixing temperature and compaction temperature range. 
The fitting formula is based on the mixing viscosity at $0.17 \pm 0.02 \mathrm{~Pa} \cdot \mathrm{s}$ (blue dotted line range) and compaction viscosity at $0.28 \pm 0.03 \mathrm{~Pa} \cdot \mathrm{s}$ (red dotted line range) as the control index, and the compaction temperature and mixing temperature of different asphalts is determined [21].

The mixing temperature of ordinary rubber asphalt is the highest, reaching $247 \sim 260{ }^{\circ} \mathrm{C}$, and the compaction temperature is also the highest, $232 \sim 243{ }^{\circ} \mathrm{C}$. The mixing and compaction temperature of stabilized rubber powder-modified asphalt is lower than that of ordinary rubber asphalt, which are $216 \sim 220{ }^{\circ} \mathrm{C}$ and $200 \sim 210{ }^{\circ} \mathrm{C}$, respectively. The mixing and compaction temperatures are about $40^{\circ} \mathrm{C}$ and $30^{\circ} \mathrm{C}$, respectively, lower than those of ordinary rubber asphalt. Its viscosity is equivalent to that of SBS-modified asphalt at $180{ }^{\circ} \mathrm{C}$, which can ensure the binding effect of stabilized rubber powder-modified asphalt on aggregate. It can be seen that the mixing temperature and compaction temperature of modified asphalt are not suitable for judging the viscosity-temperature curve, but it can be compared horizontally to show that the mixing temperature and compaction temperature of stable rubber powder-modified asphalt can be based on ordinary rubber asphalt. The $135{ }^{\circ} \mathrm{C}$ viscosity of ordinary rubber asphalt reaches $6.589 \mathrm{~Pa} \cdot \mathrm{s}$, which is far greater than the "135 ${ }^{\circ} \mathrm{C}$ viscosity not greater than $3.0 \mathrm{~Pa} \cdot \mathrm{s}^{\prime}$ " clearly stipulated in the American SHRP code and China's asphalt pavement construction code. As we all know, compaction performance is closely related to the work-ability of asphalt mixture construction. The higher the workability of asphalt mixture, the better the compaction performance. Ordinary rubber asphalt is more obvious due to its temperature sensitivity. Especially in winter construction, the construction temperature needs to be strictly controlled, and the viscosity is ensured to be in a reasonable range. Otherwise, due to the excessive viscosity during the rolling of rubber asphalt, the more obvious side swelling, rolling effect, and construction efficiency will be reduced.

\subsection{Thermal Storage Stability}

It can be seen from Figure 5 that compared with the softening point difference of the base asphalt, the softening point difference of the two rubber asphalts does not meet the requirements of the specification [20]. There are two main reasons: (1) although most of the rubber particles are swelled and decomposed at high temperature during the preparation process of rubber asphalt, a small part of the rubber powder particles still exist in the modified asphalt; and (2) the separation test was not carried out according to the specifications. It is required to pass the modified asphalt through a $0.3-\mathrm{mm}$ screen. Under high-temperature storage, the rubber powder particles are moved downwards, and the softening point indicators of the two rubber asphalts show similar rules; that is, the upper softening point value is smaller than the lower softening point value. The softening point difference of the two asphalts was compared. The softening point difference of ordinary rubber asphalt was as high as $4.8^{\circ} \mathrm{C}$, indicating that ordinary rubber asphalt does have obvious high-temperature storage stability problems. The upper and lower softening point difference of the stabilized rubber powder-modified asphalt is $2.9^{\circ} \mathrm{C}$, which is $39.58 \%$ lower than that of ordinary rubber asphalt, indicating that the use of stable rubber powder can effectively improve its high-temperature storage stability. This is because the stable rubber powder undergoes the destruction of the cross-linked grid of the rubber powder during the desulfurization process and restores many raw rubber characteristics. The stable rubber powder can fully absorb the light components of the asphalt in a short time under high-temperature shearing environment and swell and decompose. After reaching a stable state, the rubber powder swells and decomposes to a very low degree during thermal storage. 


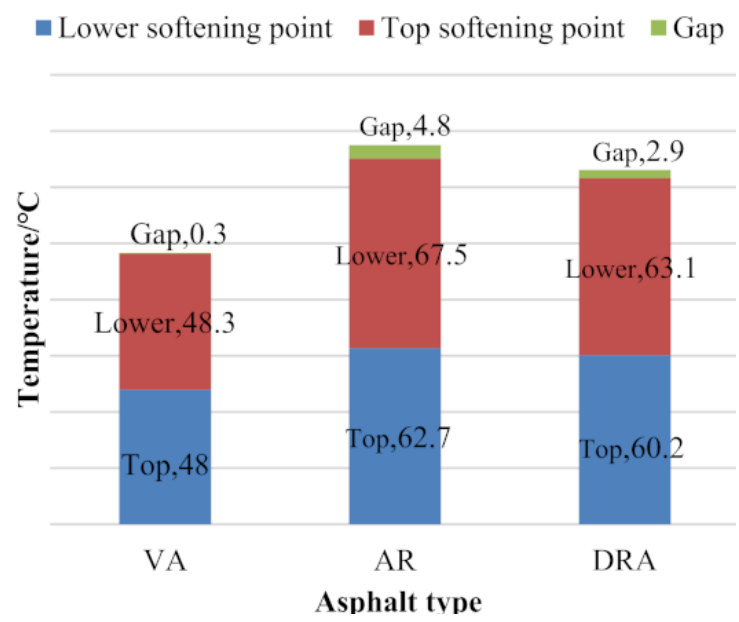

Figure 5. Segregation test results of different types of modified asphalt.

\subsection{Rubber Powder Specific Surface Area Analysis}

In general, the specific surface area of rubber powder is closely related to its modification effect on asphalt. The larger the specific surface area, the larger the contact area between rubber powder and asphalt, and the more significant the modification effect. The specific surface area of ordinary rubber powder and stable rubber powder was tested, and the test results are shown in Figure 6 and Table 6.

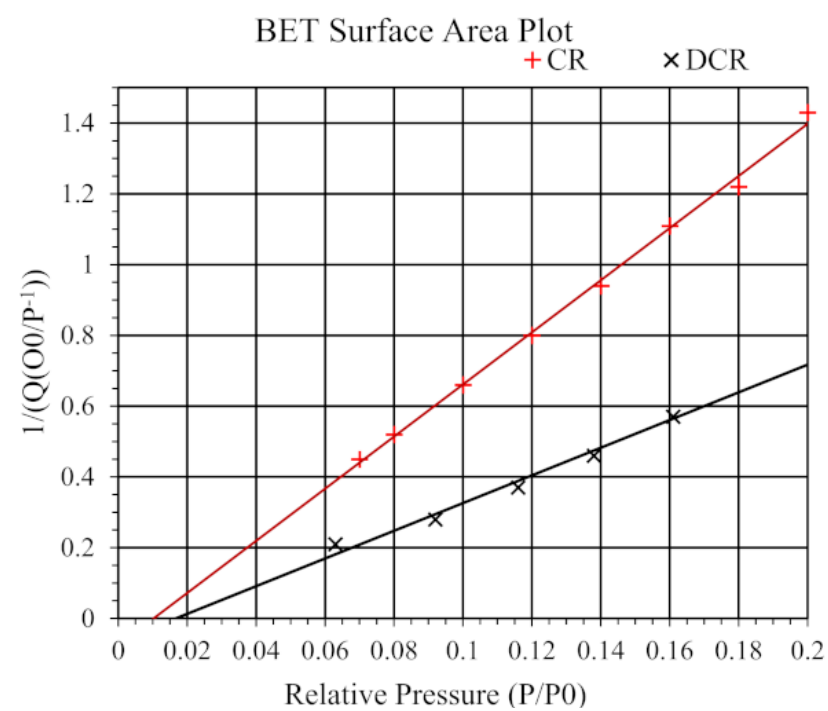

Figure 6. BET multi-point analysis diagram of two rubber powders.

Table 6. Test results of specific surface area of two rubber powders.

\begin{tabular}{|c|c|c|c|}
\hline Rubber Powder Type & $\mathrm{P} / \mathrm{P}_{0} / \mathrm{m}^{2} \cdot \mathrm{g}^{-1}$ & $\begin{array}{c}\text { Langmuir Specific } \\
\text { Surface Area } / \mathrm{m}^{2} \cdot \mathrm{g}^{-1}\end{array}$ & $\begin{array}{c}\text { BET Specific Surface } \\
\text { Area } / \mathrm{m}^{2} \cdot \mathrm{g}^{-1}\end{array}$ \\
\hline Ordinary rubber powder & 0.3292 & 0.7808 & 0.5874 \\
\hline Stable rubber powder & 0.1775 & 1.3394 & 1.0364 \\
\hline
\end{tabular}

Langmuir Equation:

$$
\mathrm{V}=\mathrm{V}_{\mathrm{L}} \mathrm{P} /\left(\mathrm{P}+\mathrm{P}_{\mathrm{L}}\right)
$$

Among them: V-Adsorption capacity, $\mathrm{m}^{3} / \mathrm{t} ; \mathrm{P}$-Adsorption pressure, $\mathrm{MPa} ; \mathrm{V}_{\mathrm{L}}$ Langmuir volume, that is, the theoretical maximum adsorption capacity, $\mathrm{m}^{3} / \mathrm{t} ; \mathrm{P}_{\mathrm{L}}$ Langmuir pressure, the adsorption pressure when the volume reaches $0.5 \mathrm{VL}, \mathrm{MPa}$. 
BET Equation:

$$
\frac{\frac{\mathrm{P}}{\mathrm{P}_{0}}}{\mathrm{~V}_{\mathrm{a}} \cdot 1-\frac{\mathrm{P}}{\mathrm{P}_{0}}}=\frac{1}{\mathrm{~V}_{\mathrm{m}} \cdot \mathrm{c}}+\frac{\mathrm{c}-1}{\mathrm{~V}_{\mathrm{m}} \cdot \mathrm{c}} \cdot \frac{\mathrm{P}}{\mathrm{P}_{0}}
$$

Among them: $\mathrm{V}_{\mathrm{m}}-$ Monolayer adsorption capacity, $\mathrm{cm}^{3}-\mathrm{STP} \cdot \mathrm{g}^{-1} ; \mathrm{V}_{\mathrm{a}}-\mathrm{Nitrogen}$ adsorption capacity, $\mathrm{cm}^{3}-\mathrm{STP} \cdot \mathrm{g}^{-1} ; \mathrm{P}_{0}$-Saturated vapor pressure, $\mathrm{kPa} ; \mathrm{P}$-Balance pressure, $\mathrm{kPa}$; C-Constant related to the net molar heat of adsorption of nitrogen.

The data in Figure 6 and Table 6 are combined, and the Langmuir formula (Equation (1)) is calculated according to the calculation, and the specific surface area of ordinary rubber powder is $0.7808 \mathrm{~m}^{2} / \mathrm{g}$, and the specific surface area of stable rubber powder is $1.3394 \mathrm{~m}^{2} / \mathrm{g}$. The BET formula is calculated according to (Equation (2)), the specific surface area of ordinary rubber powder is $0.5874 \mathrm{~m}^{2} / \mathrm{g}$, and the specific surface area of stable rubber powder is $1.0364 \mathrm{~m}^{2} / \mathrm{g}$. The specific surface area of stabilized rubber powder after desulfurization activation process is 1.76 times that of ordinary rubber powder, indicating that the desulfurization effect increases the porosity of the rubber powder particles and the surface structure is fluffier. The intuitive touch is that the stable rubber powder has a certain elasticity. Therefore, the stable rubber powder has the advantage of a larger contact area between the ordinary rubber powder and the asphalt matrix, which enhances the compatibility of the stable rubber powder with the asphalt.

\subsection{Analysis of Microscopic Morphology of Stable Rubber Powder-Modified Asphalt}

Ordinary rubber powder is made by crushing waste rubber products with shear force at room temperature, and the surface of the ground rubber has not been severely damaged. Therefore, the surface of ordinary rubber powder is relatively dense and exhibits relatively obvious edges and corners, and the contact area with the asphalt matrix is small, and it is not easy to mix with it. After the stable rubber powder is re-pelleted by the purely physical thermostatically twin-screw extrusion method, the internal molecular chain is damaged, the surface of the rubber powder is uneven, showing a fluffy aggregate shape, the specific surface area is relatively increased, and it is in contact with the asphalt matrix. The area becomes larger. This is consistent with the analysis results of the specific surface area of the rubber powder in Section 3.4, as shown in Figures 7 and 8 below.

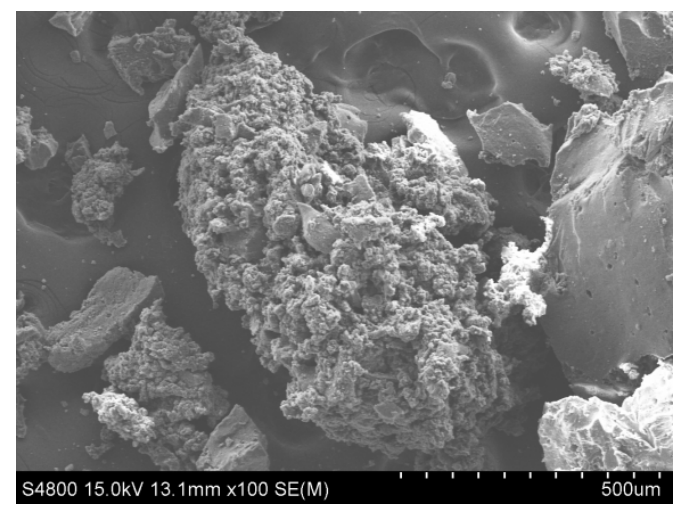

Figure 7. Micro morphology of rubber powder $(\times 100)$.

The two rubber asphalt samples were first subjected to a simple elution process. The asphalt samples of the same quality were eluted and filtered with organic solvents, and then, the filter paper was placed in an oven at $100{ }^{\circ} \mathrm{C}$ and fully dried.

On this basis, the SEM microscopic test was carried out, and the test photo is shown in Figure 9. 


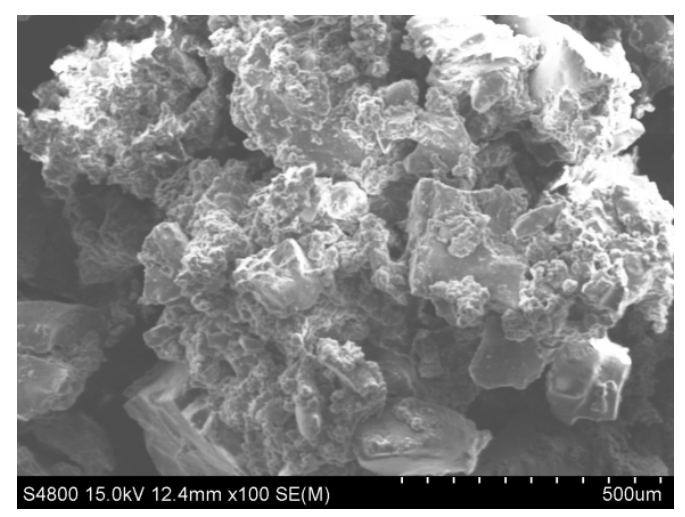

Figure 8. Micro morphology of stabilized rubber powder $(\times 100)$.
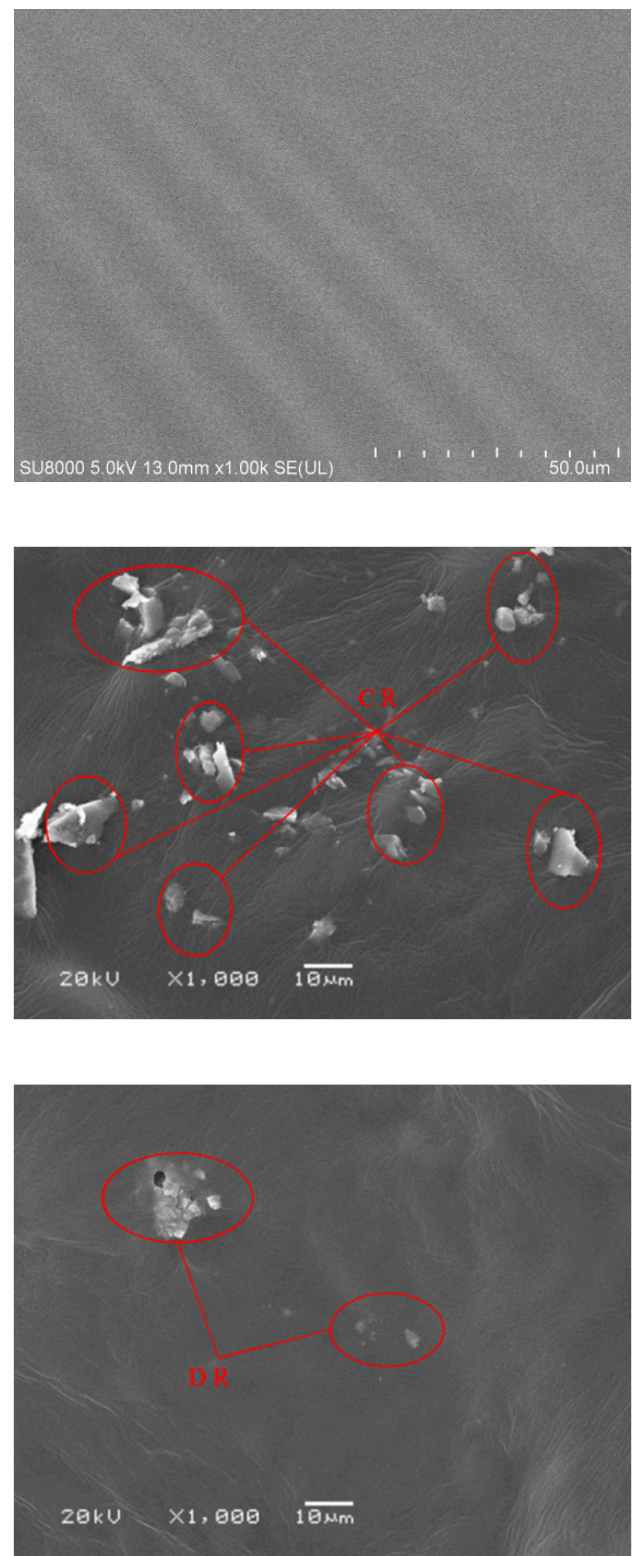

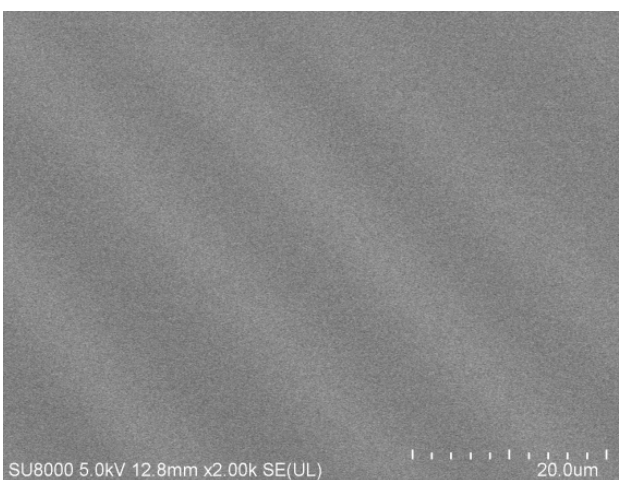

(a)

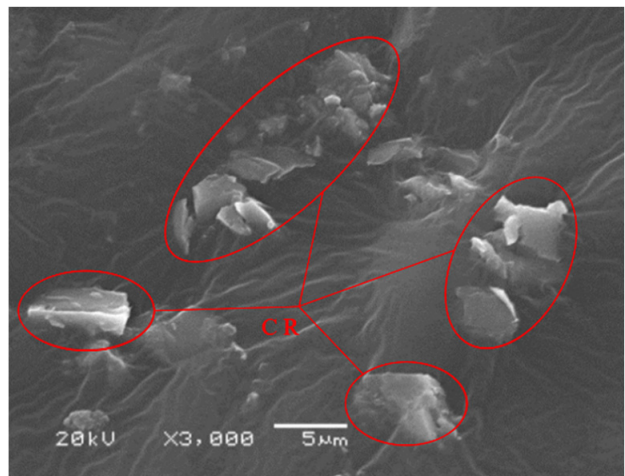

(b)

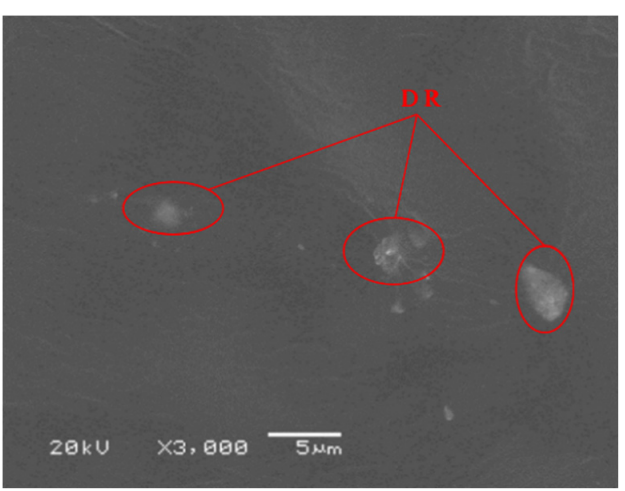

(c)

Figure 9. SEM photos of different types of asphalt. (a) Scanning electron microscope pictures of VA (left $\times 1000$, right $\times 2000$ ). (b) Scanning electron microscope pictures of AR (left $\times 1000$, right $\times 3000)$. (c) Scanning electron microscope pictures of DRA (left $\times 1000$, right $\times 3000$ ). 
It can be clearly seen from Figure 9 that the surface smoothness of ordinary rubber asphalt and stabilized rubber powder-modified asphalt is different, and the surface is rougher after adding rubber powder. A large number of solid rubber particles can be seen in ordinary rubber asphalt (the red circle in Figure $9 \mathrm{~b}$ is marked as CR). Most of the rubber powder particles are larger than $0.01 \mathrm{~mm}$, and these particles are in contact with each other. It can be seen from Figure $9 \mathrm{~b}$ that the ordinary rubber powder particles have obvious edges and corners after high-temperature shearing, and the shearing marks are obvious, and the rubber powder particles have swelled in different degrees of volume. It is mainly in the form of an enlarged gel particle core with large particles as the center and small particles distributed around. The main reason is that the rubber particles are cut into pieces due to mechanical and physical effects. In the stabilized rubber powder-modified asphalt, the particle state of the rubber powder is significantly reduced and dispersed evenly (the red circle in Figure 9c is marked as DR), and the surface of the stabilized rubber powder is relatively fluffy. In the comparison presented in Figure $9 b, c$, the common rubber asphalt has a great deal of wrinkles. The rubber powder surface is bright, and the contact surface with the asphalt is clear, while the stabilized rubber powder-modified asphalt is smoother. It shows that ordinary rubber asphalt is mainly based on oil absorption swelling mechanism and network filling mechanism.

\subsection{Thermal Stability of Stabilized Rubber Powder-Modified Asphalt}

It can be seen from Figure 10 that the thermal analysis pattern trend of the stabilized rubber powder-modified asphalt is roughly the same as that of the ordinary rubber asphalt, but the change trend is relatively gentle. The main reason is that the S-S and C-S bonds of the stable rubber powder have been destroyed under the thermal energy and strong shear provided by the twin-screw extruder, allowing the vulcanized rubber to recover part of its plasticity and viscosity. Integrating the DSC curve can obtain the amount of energy required for the phase transition of the modified asphalt, the stable rubber powder-modified asphalt requires less energy in the test temperature range of room temperature to $600{ }^{\circ} \mathrm{C}$, indicating that the stable rubber powder has the ability to produce physical and chemical reactions more easily than ordinary rubber and base asphalt. It can be seen from the TG curve that the temperature at which the mass loss of the sample occurs is about $220^{\circ} \mathrm{C}$, which is about $30^{\circ} \mathrm{C}$ earlier than ordinary rubber asphalt. On the one hand, it is because the stable rubber powder and asphalt are more compatible, and the material exchange between the two is faster. On the other hand, since the content of natural rubber (NR) in the stable rubber powder is higher than that of the ordinary rubber powder, as the decomposition temperature increases, the chain scission process of the rubber powder-modified asphalt first occurs at the structure where NR exists. The interaction between them is more intense.

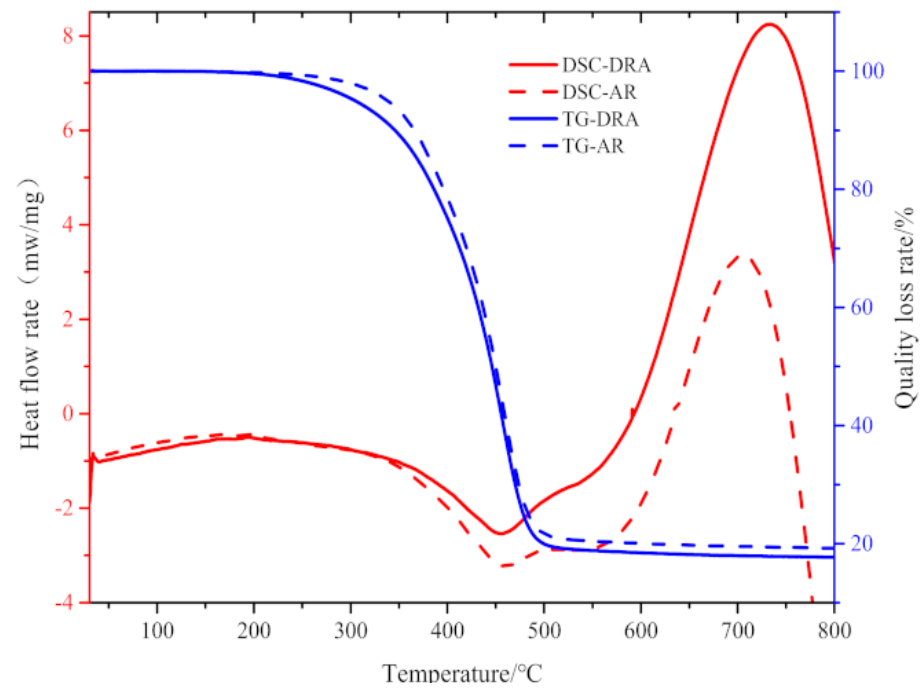

Figure 10. Thermal analysis spectra of two rubber asphalt. 


\section{Conclusions}

(1) Experimental studies have shown that the temperature sensitivity of the stabilized rubber powder added to the asphalt has been improved, the high- and low-temperature performance has been improved, and the problem of excessive viscosity at $135^{\circ} \mathrm{C}$ has been effectively reduced. According to the test results, the recommended dosage is $30 \%$ stable rubber powder.

(2) As the test temperature is lowered, the Brookfield viscosity of the stabilized rubber powder-modified asphalt is continuously increased. However, the range of change is smaller than that of ordinary rubber asphalt, so the temperature control should be strict to ensure the viscosity of the stabilized rubber powder-modified asphalt.

(3) The specific surface area comparison test shows that the stable rubber powder has the advantage of larger contact area between the ordinary rubber powder and the asphalt matrix, and the compatibility of the stable rubber powder with the asphalt is enhanced.

(4) Scanning electron microscopy and differential scanning calorimetry test results show that the compatibility mechanism is the main stable rubber powder-modified asphalt. The series of processes of oil absorption swelling, high-temperature, shear-compatible dispersion are mainly occurred. The microscopic morphology and aggregation transformation of the stabilized rubber powder-modified asphalt are analyzed. The oil absorption swelling mechanism is the main reason for the stable rubber powder-modified asphalt in the initial preparation stage, and the compatibility and stability mechanism is mainly used in the thermal storage stage.

Author Contributions: Methodology, Z.G. and P.G.; formal analysis, F.Y.; data curation, H.L.; writing—original draft preparation, F.Y. and Q.M.; writing—review and editing, H.L. and Q.M. All authors have read and agreed to the published version of the manuscript.

Funding: This study is sponsored by Transportation Technology Project of Shaanxi Province (Grand No 16-41T, 19-10K), Shaanxi Province Innovation Capability Support Plan (2019KJXX-035).

Institutional Review Board Statement: Not applicable.

Informed Consent Statement: Not applicable.

Data Availability Statement: No data were used to support this study.

Conflicts of Interest: The authors declare that they have no conflict of interest.

\section{References}

1. Li, H.; Zhang, F.; Feng, Z.; Li, W.; Zou, X. Study on waste engine oil and waste cooking oil on performance improvement of aged asphalt and application in reclaimed asphalt mixture. Constr. Build. Mater. 2021, 276, 122138. [CrossRef]

2. Li, H.; Wang, W.; Li, W.; Taoum, A.; Zhao, G.; Guo, P. Replacement of limestone with volcanic stone in asphalt mastic used for road pavement. Arab. J. Sci. Eng. 2019, 44, 8629-8644. [CrossRef]

3. Yang, F.; Li, H.; Zhao, G.; Guo, P.; Li, W. Mechanical performance and durability evaluation of sandstone concrete. Adv. Mater. Sci. Eng. 2020, 2020, 1-10. [CrossRef]

4. Li, H.; Liu, G.; Dong, B.; Zhao, G.; Guo, P.; Huang, J.; Sheng, Y. Research on the development and regeneration performance of asphalt rejuvenator based on the mixed waste engine oil and waste cooking oil. Int. J. Pavement Res. Technol. 2019, 12, 336-346. [CrossRef]

5. Li, H.; Dong, B.; Zhao, D.; Guo, P.; Zhang, J. Physical, Rheological and Stability Properties of Desulfurized Rubber Asphalt and Crumb Rubber Asphalt. Arab. J. Sci. Eng. 2019, 44, 5043-5056. [CrossRef]

6. Al-Khateeb, G.G.; Ramadan, K.Z. Investigation of the effect of rubber on rheological properties of asphalt binders using superpave dsr. KSCE J. Civ. Eng. 2015, 19, 127-135. [CrossRef]

7. Zhou, T.; Zhou, J.; Li, Q.; Li, B. Aging Properties and Mechanism of Microwave-Activated Crumb Rubber Modified Asphalt Binder. Front. Mater. 2020, 7, 603938. [CrossRef]

8. Jeong, K.-D.; Lee, S.-J.; Amirkhanian, S.N.; Kim, K.W. Interaction effects of crumb rubber modified asphalt binders. Constr. Build. Mater. 2010, 24, 824-831. [CrossRef]

9. Ibrahim, I.M.; Fathy, E.S.; El-Shafie, M.; Elnaggar, M.Y. Impact of incorporated gamma irradiated crumb rubber on theshort-term aging resistance and rheological properties of asphalt binder. Constr. Build. Mater. 2015, 81, 42-46. [CrossRef] 
10. Ahmed, T.; Bahzad, D.; Al-Marshed, A.; Omar, M. Evaluating the Characteristics of Crumb Rubber Modified Asphalt Binders Produced with Neat Bitumen-Case of Kuwait. In Proceedings of the 9th International Conference on Maintenance and Rehabilitation of Pavements-Mairepav9, Zurich, Switzerland, 1-3 July 2020; Springer: Cham, Switzerland, 2020; Volume 14, pp. 513-518.

11. Gallego, J.; Rodríguez-Alloza, A.M.; Giuliani, F. Black curves and creep behaviour of crumb rubber modified binders containing warm mix asphalt additives. Mech. Time-Depend. Mater. 2016, 20, 389-403. [CrossRef]

12. Shatanawi, K.; Biro, S.; Thodesen, C.; Amirkhanian, S. Effects of Water Activation of Crumb Rubber on the Properties of Crumb Rubber-Modified Binders. Int. J. Pavement Eng. 2009, 10, 289-297. [CrossRef]

13. Wang, X.; Lv, X.; Chu, F. Analysis of performance characteristics of different types of rubber powder and SBS composite modified asphalt. Bull. Chin. Ceram. Soc. 2019, 38, 3695-3702.

14. Zhang, X.; Chen, H.; Zhang, B. Research on the road performance of TOR modified waste car tire rubber asphalt mixture. Bull. Ceram. 2018, 37, 2241-2247.

15. Li, B.; Li, P.; Zhang, X. The effect of the reaction and crosslinking of waste rubber powder on the viscosity of rubber asphalt. $J$. Chang. Univ. (Nat. Sci. Ed.) 2017, 37, 26-34.

16. Dong, B. Research on the Characteristics of Stable Rubber Powder Modified Asphalt and Its Mixture Performance. Master's Thesis, Xi'an University of Science and Technology, Xi'an, China, 2020.

17. Zhang, Q.; Hou, D.; Shi, J. Overview of the micro characterization methods and micro characteristics of rubber asphalt. Mater. Guide 2019, 33, 247-253.

18. Li, H.; Li, W.; Temitope, A.A.; Zhao, D.; Zhao, G.; Ma, Q. Analysis of the influence of production method, crumb rubber content and stabilizer on the performance of asphalt rubber. Appl. Sci. 2020, 10, 5447. [CrossRef]

19. JTG E20-2019. Highway Engineering Asphalt and Mixture Test Regulations; People's Communications Press: Beijing, China, 2019.

20. DB 61/T 1021-2016. Technical Specification for Rubber Asphalt Pavement Construction; Shaanxi Provincial Bureau of Quality and Technical Supervision: Xi'an, China, 2016.

21. Li, H.; Dong, B.; Wang, W.; Zhao, G.; Guo, P.; Ma, Q. Effect of waste engine oil and waste cooking oil on performance improvement of aged asphalt. Appl. Sci. 2019, 9, 1767. [CrossRef] 